\title{
John M. Steele, editor, The Circulation of Astronomical Knowledge in the Ancient World
}

Leiden: Brill, 2016. Hardback 586 pp, illustrations. ISBN: 978-90-04-315617; E-book: E-ISBN: $9789004315631 . € 189$ / \$223 US.

\section{Robert Hannah}

Emeritus Professor University of Waikato (New Zealand) roberth@waikato.ac.nz

This book derives from a conference held at Brown University in 2014. The conference brought together scholars from both Western and Eastern traditions of astronomy, as the spread of topics in the proceedings under review illustrates. After an introductory historiographical essay on "The Brown School of the History of Science" by Francesca Rochberg, there follow five presentations on Mesopotamian astronomy (Rutz, Wainer, Steele, Monroe and Wee), two on Egyptian (Quack and Winkler), two on Greek (Montelle and Jones), four on the reception of Mesopotamian or Greek astronomy (Misiewicz, Harkness, Song and Niu), two on Chinese (Morgan and Guan), and one on Indian (Duke).

The past two or three decades have seen an increasing tendency for Western scholars to engage with South and East Asian astronomical records, sometimes to confirm theories about events in the West such as comet sightings and, at other times, to work directly and intrinsically with the astronomy of the region. This has matured into collaborations, particularly with Indian and Chinese scholars and scholarship. We see the fruits of such developments in both Western and Chinese scholarship in this volume. While there is just one paper specifically on Indian astronomy in this volume (Chapter 17 - Duke, "Were Planetary Models of Ancient India Strongly Influenced by Greek Astronomy?"), nonetheless it also gains mention and discussion in Chapter 9 ("The Anaphoricus of Hypsicles of Alexandria") by Montelle, who also works in the Indian tradition.

The "Introduction" (presumably by John Steele, although it is not attributed) focuses on the question of "circulation" of astronomical and astrological knowledge, which the book's title promotes as the theme around which the various contributions are intended to congregate. Steele states that he uses the term "circulation" deliberately, "to emphasize that the transmission of knowledge is not a unidirectional process: astronomical knowledge from one group is not imposed upon another group; rather the process is one of negotiation between the two parties" (p. 1). This is picked up further by Rochberg 
in the opening chapter, "The Brown School of the History of Science: Historiography and the Astral Sciences", but, just from Steele's initial brief analysis of the idea of "circulation", it is clear that we have moved on from the focus on purely mathematical astronomy which marked the work of Otto Neugebauer. Rather, Steele emphasises how we need to understand the broader historical and cultural contexts within which the transmission of ideas and data occurred. Neugebauer was by no means ignorant of this cultural context, particularly with regard to Greek and Babylonian astronomy and astrology, but at times he seems to have had a blind spot with regard to some cultural demonstrations of astronomical knowledge. I am thinking here of his approach to Egyptian astronomy. Quack's paper, "On the Concomitancy of the Seemingly Incommensurable, or Why Egyptian Astral Tradition Needs to be Analyzed within Its Cultural Context", in this volume is a particularly welcome antidote to Neugebauer's famous dismissal of Egyptian astronomy in a handful of pages in his magisterial and, rightly, still influential A History of Ancient Mathematical Astronomy (Neugebauer 1975). Quack draws to our attention the increased number of papyri available now which indicate the complexity of Egyptian astronomy, but also the need to understand its scientific character within its own cultural setting. In this book, "culture" can refer not only to that of a whole country (China), but even to that of a small city (Uruk), which is appropriate under the circumstances.

In Rochberg's historiographical analysis of the so-called "Brown School" within Brown University's History of Mathematics Department, she focuses on its first and last members: Neugebauer, the famous and formidable founder, and David Pingree, its last member in residence before a hiatus which followed his death, and which fortunately ended with the more recent appointment of John Steele to Brown's Department of Egyptology and Assyriology. She hints at others who were influenced by or collaborated with the "Brown School" but worked elsewhere, and I note the presence in the conference team of Pingree's last PhD student at Brown, Clemency Montelle, now based in New Zealand. The focus on Neugebauer and Pingree is not to diminish the contributions of other members of the same department (for example, Abraham Sachs and Gerald Toomer) whose work overall increased our awareness of how much astronomical knowledge was transmitted between Mesopotamia, Greece, India and the medieval worlds of Europe and Islam, but rather to draw out a distinction between the preconceptions about "science" held by Neugebauer and Pingree. For while the two did much to shift twentieth-century perceptions of "science" from a practice seen simply as a heritage of a purely Greek way of thinking through their extension of our knowledge of Western and South Asian ways of thinking about the world of knowledge, nonetheless, as Rochberg shows, they differed in their appreciation of what "science" is; Neugebauer saw it as a unity irrespective of any cultural contexts, while Pingree saw its geographical disunity and its cultural constructedness.

Rochberg also teases out distinctions between "transmission" and "reception", in an effort to define better what this conference and its resulting book are all about: what does it mean to have knowledge "circulating" from one culture to another and back or within a culture? The dynamic nature of the circulation of knowledge between peoples, Rochberg feels, is not captured by the terms "transmission" and "reception", as the recipients of 
new knowledge can too often be regarded as passive receivers, not active adapters and re-creators of that knowledge. Not all papers deal with this core theme in the same depth - at times, it feels like an add-on to a quite distinct case study in one culture's development of astronomy or astrology and, sometimes, it is absent altogether, as in Winkler's otherwise instructive paper on Egyptian astrological handbooks, "Some Astrologers and Their Handbooks in Demotic Egyptian".

Just how active the receivers of others' astronomical or astrological knowledge were is demonstrated by a number of the papers. Rutz, in "Astral Knowledge in an International Age: Transmission of the Cuneiform Tradition, c. 1500-1000 BC", charts the transmission of Mesopotamian knowledge to other parts of the Near East in the second half of the second millennium BC, the so-called "Amarna Period", "the ancient Near East's first great international age" (p. 18), when people, objects (including cuneiform tablets) and, hence, knowledge circulated across a widespread region of the Near East. He focuses on the absorption of Babylonian and Assyrian astral knowledge as evidenced in the remains from Emar, Ugarit and Hattuša, where issues of translation and comprehension necessarily arose.

In her chapter "The Anaphoricus of Hypsicles of Alexandria", Montelle investigates the transmission to the Greek world of Babylonian schemes for the rising times of the ecliptic, providing en route a useful translation and commentary on a Greek text, Hypsicles of Alexandria's Anaphoricus, which is also the earliest surviving work demonstrating the major influence of Near Eastern astronomy on Greece. She also teases out the curious nature of this small work, that it was popular over a long period of time despite not being the most up-to-date analysis of the mathematics of the rising times for stars, because it kept things simple.

Whether Greek models of planetary positions lie behind later Indian ones has been debated for a long time, with a West-East divide in opinion developing in the twentieth century, as Western scholars perceived Greek influence on India and Eastern scholars saw Indian developments as indigenous. For Duke, the dependence of the Indian planetary model (which he calls "4-step", after the four-step procedure underlying it [p. 563]) on the equant, for which there is no evidence of indigenous development in India but plenty in the Greco-Roman world, argues for outside and probably Greek influence on Indian astronomers in the development of their planetary models.

Different forms of Mesopotamian celestial divination are the subject of Misiewicz's and Wainer's papers. In "Mesopotamian Lunar Omens in Justinian's Constantinople", Misiewicz examines in detail the possibility of transmission of Mesopotamian "universal celestial omens" (which associate a particular celestial phenomenon with an outcome relevant for a region as a whole, rather than a single individual) in the work of John of Lydus in sixth-century AD Constantinople. She thus extends the century-old standard study of Bezold and Boll (1911) on such transmission by going beyond their search for evidence of direct transmission of individual sentences of omen texts from the Akkadian to the Greek corpus, to a search for the repetition of overall structure and content in the work of Lydus in particular. Misiewicz focuses her attention on four parts: the overall structure of the texts, the temporal elements included within the omens, the lunar phenomena 
of the protases ("if the moon appears dim during the first or second watch..."), and the terrestrial phenomena of the apodoses ("...there will be war") (pp. 365-366). The result of her investigation is rather more intriguing than a story of simple, direct transmission, and shows how culturally constructed knowledge is: although an Anatolian by birth, Greek by language and Christian by religious persuasion, Lydus saw himself as a Roman and emphasised Italian (i.e. Etruscan) origins for the omen literature that he presented. While close similarities can be demonstrated between at least one text included in his compendium and the Mesopotamian omen tradition, as represented by texts from the Neo-Assyrian period, nonetheless "these similarities are not close enough to suggest a straightforward copying of some Mesopotamian source-text, but instead point to a more general circulation of the concepts of celestial omen interpretation, as might be expected given the large gap in time and space that separates the texts" (p. 393).

Alternative modes of celestial divination beyond the typical omen-type ("if $P$, then $\mathrm{Q}^{\prime}$ ) are the subject of Wainer's paper, "Traditions of Mesopotamian Celestial-Divinatory Schemes and the 4th Tablet of Šumma Sin ina Tāmartišu". These "schemes" take the form of a celestial phenomenon (for example, an eclipse) at a certain time (the first watch of the night) and its perceived associations (deaths, or the land of Akkad). There is prima facie similarity with the typical omen-type, and the simplicity of the scheme-type might suggest it was the basis for the verbally more complicated omen-type, but Wainer argues that there is little evidence for this and points out that instead the two types co-existed and schemes were used in conjunction with omens. Both types were transmitted for more than a millennium and both preserved stable contents. Both were also extended to interpret phenomena which were not originally the object of interpretation.

Transmission, however, is only a first step. After transmission, Steele notes in his "Introduction" (p. 2), knowledge is adapted, even "naturalized", to its new cultural setting. The papers by Song and Niu illustrate this process, where Western or Indian knowledge are "Sinicized" in China. Song, in "The Twelve Signs of the Zodiac during the Tang and Song Dynasties: A Set of Signs Which Lost Their Meanings within Chinese Horoscopic Astrology", deals with the introduction of the Hellenistic-Indian zodiac to horoscopic astrology in Tang and Song China (618-1279 AD). Here, the twelve signs came to be associated with traditional concepts of Chinese divination such as the Five Phases (mù [wood], huǒ [fire], tǔ [earth], jin [metal] and shuǐ [water]) and the twelve Earthly Branches used to define direction and time, (zĭ, chǒu, yín, măo, chén, sì, wŭ, wèi, shēn, yǒu, xū, hài). In the process, he finds that the zodiacal signs lost their original horoscopic meanings. Niu's paper "On the Dunhuang Manuscript P.4017: A Case Study on the Sinicization of Western Horoscope in Late 10th Century China", in effect presents a case study of such adaptations of Hellenistic-Indian astrology in China through a very detailed analysis of a natal horoscope in the tenth-century AD Dunhuang Manuscript P.4017.

Steele's own paper "The Circulation of Astronomical Knowledge between Babylon and Uruk" and that of Monroe, "The Micro-Zodiac in Babylon and Uruk: Seleucid Zodiacal Astrology", also deal with this "naturalization" of knowledge, but between just two cities within Babylonia, Babylon and Uruk - a reminder of how geographically-localised "culture" usually was in the pre-modern world. The process of adaptation is further 
demonstrated in the papers of Wee ("Virtual Moons over Babylonia: The Calendar Text System, Its Micro-Zodiac of 13, and the Making of Medical Zodiology") and Harkness ("A Parallel Universe: The Transmission of Astronomical Terminology in Early Chinese Almanacs"), who examine the incorporation of specific aspects of astrological or astronomical knowledge.

Culture is also localised across time, so that the absorption of astronomical or astrological knowledge by later peoples can be a process fraught with issues of loss, translation of technical terms and, even, of the disconnect of underlying worldviews. Jones, in "Interpolated Observations and Historical Observational Records in Ptolemy's Astronomy", indicates how surprisingly poor (given the modern perceptions of the astronomer and of Alexandria as a centre of learning) Ptolemy's access to extensive records of direct observations was for some of his investigations into solstices, equinoxes, greatest elongations and oppositions. Jones shows how Ptolemy was forced to interpolate between observations when specific observations were not available. The complexity of older traditions and, especially, the framework into which later periods (our own included) have sought to straitjacket them are the subject of Morgan's paper on Imperial Chinese planetary models, entitled "Mercury and the Case for Plural Planetary Traditions in Early Imperial China". His admonition (p. 445) that we should seek to view these traditions as they were seen originally and not impose on them anachronistic or culturally unsound concepts (such as even "authorship" on what was a received tradition of anonymous material) is well taken. Tradition was also an important constraint on astronomically based calendar systems. This is demonstrated by Guan in "Calendrical Systems in Early Imperial China: Reform, Evaluation and Tradition" with regard to the reforms of official calendars in Early Imperial China. New calendrical systems and calculations had to take their place alongside other traditionally valued political and cultural standards or against older valued theories such as calculations involving solstices, lunations or eclipse predictions.

The various sub-themes that can be discerned among the papers in this volume show how interconnected the issues facing Western and Eastern scholars of ancient astronomy and astrology are, and it is a notable benefit of this publication that such similarities can be discerned. But more could have been done to show this interconnectedness. There is no engagement, for example, between papers which share the same theme - Misiewicz (p. 350) refers readers to Rochberg (2010) on an item such as the micro-zodiac (by which each of the twelve signs of the zodiac is divided into twelfths, which are named after the twelve signs), but not to Monroe or Wee, who deal in depth with this concept in this volume; and even between Monroe and Wee there is no cross-reference. Similarly, Song and Niu write in a vacuum from each other, despite Niu's paper illustrating in great detail the sort of adaptations of Hellenistic-Indian astrology in China that Song outlines. The only cross-reference that I noticed is a reference by Quack to Winkler's paper, but it is only for Quack to say that, therefore, he will not deal with the latter's topic. Nor is there any sense of the dialogue which ensued in the discussions after each paper at the conference and how these discussions may have affected an individual presenter's thoughts between presentation and publication. Undoubtedly, each paper is interesting and valuable in itself and adds to our understanding of astronomy in its broadest sense 
across the ancient Old World, but I feel an opportunity to make the conference publication add up to more than just the sum of parts has gone begging, as has the chance to foster for readers greater understanding between the different scholarships.

Most papers are of roughly the same length (30-45 pages), although a couple are shorter (only about 15 pages), while Wee's runs to 90 pages and would have benefited from some tighter editing. Production quality is generally very good, except for the number of typographical errors which occur throughout the volume. An oddity is that there are no biographies of the authors nor even an indication of academic affiliation, at least in the e-book version given to this reviewer.

\section{References}

Bezold, C. and F. Boll, 1911. "Reflexe astrologischer Keilinschriften bei griechischen Schriftstellern". Sitzungsberichte der Heidelberger Akademie der Wissenschaften 7: 1-54.

Neugebauer, O., 1975. A History of Ancient Mathematical Astronomy. Berlin: Springer. https://doi.org/ 10.1007/978-3-642-61910-6

Rochberg, F., 2010. In the Path of the Moon: Babylonian Celestial Divination and Its Legacy. Leiden: Brill. https:// doi.org/10.1163/ej.9789004183896.i-445 